\title{
DESAIN PENGENDALI UNTUK NETWORKED CONTROL SYSTEM MENGGUNAKAN PENDEKATAN MARKOVIAN JUMP SYSTEM
}

\author{
Asep Najmurrokhman \\ Jurusan Teknik Elektro, Fakultas Teknik, Universitas Jenderal Achmad Yani \\ asepnajmu@yahoo.com
}

\begin{abstract}
Abstrak
Dewasa ini, perkembangan sistem kendali yang diterapkan dalam industri modern mengarah kepada pemanfaatan jaringan komunikasi untuk menghubungkan antar bagian dalam sistem. Sistem kendali yang memanfaatkan jaringan komunikasi sebagai bagian dari lingkar kendali disebut networked control system (NCS). Penggunaan jaringan komunikasi, selain memberikan kemanfaatan dalam beberapa hal seperti kemudahan dalam pemeliharaan, reduksi biaya instalasi, modularisasi sistem, dan lain-lain, memunculkan parameter jaringan komunikasi yang tidak bisa dihindarkan seperti waktu tunda transmisi, kemungkinan hilangnya paket data yang dikirim (packet loss), terbatasnya lebar pita frekuensi, dan sebagainya. Makalah ini memaparkan desain pengendali untuk NCS dengan menggunakan umpan balik keadaan agar diperoleh tujuan pengendalian lingkar tertutupnya. Karena sifat stokastik dari parameter jaringan komunikasi, pemodelan NCS menggunakan pendekatan Markovian jump system (MJS). Selanjutnya, analisis dan sintesis sistem NCS menggunakan formulasi pertidaksamaan matriks linier. Hasil utama dari makalah ini berupa kondisi solusi dalam bentuk pertidaksamaan matriks linier agar diperoleh sebuah pengendali dengan umpan balik keadaan yang menghasilkan kinerja tertentu dari sistem NCS lingkar tertutupnya. Sebuah contoh numerik diberikan untuk mengilustrasikan keefektifan dari metode perancangan yang diuraikan dalam makalah ini.
\end{abstract}

Kata kunci : disipativitas, Markovian jump system (MJS), networked control system (NCS), pertidaksamaan matriks linier.

\section{Pendahuluan}

Dalam dekade terakhir, internet telah menjadi jaringan komunikasi yang paling berhasil dalam menghubungkan dan mempertukarkan informasi antar pengguna dalam jumlah dan variasi yang tidak terbatas [1]. Perpustakaan online dapat diakses dalam hitungan detik serta berkas audio dan video dapat dibagikan kepada jutaan orang dalam sekejap. Popularitas internet sebagai media untuk penyebaran informasi dan komunikasi telah menjadikan internet berada dimana-mana (ubiquitous) di planet bumi ini. Dengan memasang access point dan rangkaian antarmuka yang sesuai, internet dapat dimanfaatkan untuk mengendalikan peralatan dalam suatu industri atau digunakan sebagai media laboratorium virtual. Penggunaan jaringan komunikasi termasuk didalamnya internet dalam sistem kendali disebut networked control systems (NCS) [2]. Secara skematik, NCS diperlihatkan pada Gambar 1. Dalam arsitektur tersebut, plant (objek yang akan dikendalikan) beserta aktuator dan sensornya diletakkan terpisah secara spasial dengan pengendalinya. Transmisi data antar bagian dalam sistem tersebut menggunakan jaringan komunikasi yang digunakan secara bersama-sama dengan sistem lainnya.

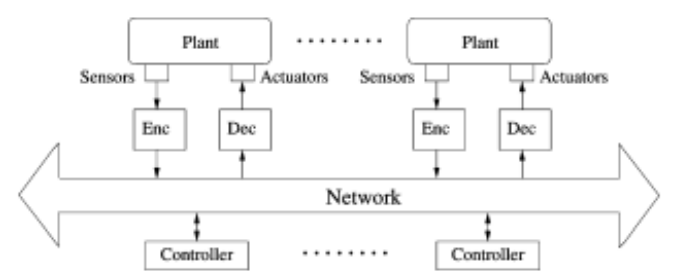

Gambar 1. Arsitektur NCS secara umum [2]

Penggunaan jaringan komunikasi menawarkan keuntungan yang cukup signifikan dalam hal keandalan, penggunaan sumber daya, pemeliharaan, diagnosa sistem apabila terjadi kesalahan, dan sebagainya [3]. Aplikasi NCS dapat ditemukan dalam kendaraaan yang menerapkan kendali otomatis, robotika, pesawat udara nirawak (unmanned aerial vehicle), jaringan sensor nirkabel, dan sebagainya [4]. Disamping keuntungan yang ditawarkan, ada beberapa parameter yang muncul dalam jaringan komunikasi seperti waktu tunda transmisi dan kemungkinan hilangnya data saat transmisi yang bisa menyebabkan penurunan kinerja 
sistem dan bahkan bisa menyebabkan ketidakstabilan [3]. Heemels, dkk. dalam [5] menyimpulkan beberapa parameter jaringan yang harus dipertimbangkan meliputi waktu tunda transmisi data yang bervariasi, adanya kemungkinan data hilang (yang disebut packet dropout) di tengah jalan akibat ketidakhandalan jaringan, adanya error kuantisasi disebabkan keterbatasan panjang kata (finite word length), interval pencacahan yang berubah-ubah secara acak, dan penggunaan bersama jaringan oleh beberapa komponen (multi nodes). Dengan demikian, keberhasilan penerapan NCS ditentukan oleh metode perancangan pengendali yang mempertimbangkan keberadaan parameter jaringan komunikasi tersebut.

Makalah ini memaparkan salahsatu teknik perancangan pengendali dalam sistem NCS untuk menghasilkan tujuan pengendalian lingkar tertutupnya. Parameter jaringan komunikasi yang dipertimbangkan dalam penelitian ini adalah kemungkinan hilangnya paket data (packet loss) saat transmisi antara sensor ke pengendali dan dari pengendali ke aktuator. Pengendali dikonstruksi melalui formulasi pertidaksamaan matriks linier.

\section{Pemodelan NCS dengan Markovian jump system}

Secara sederhana, diagram blok NCS diilustrasikan pada Gambar 2. Sinyal $\mathrm{u}_{\mathrm{i}}, \mathrm{w}_{\mathrm{i}}, \mathrm{y}_{\mathrm{i}}$, dan $\mathrm{v}_{\mathrm{i}}$ berturut-turut menandai input ke aktuator, input ke pengendali, output dari sensor, dan output pengendali. Sinyal $y_{i}$ adalah data pengukuran yang dilakukan oleh sensor, sedangkan sinyal $u_{i}$ adalah sinyal kendali dihitung oleh pengendali dan diberikan kepada aktuator.

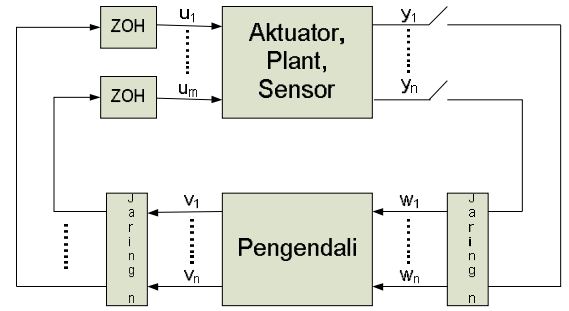

Gambar 2. Diagram blok NCS

Pemodelan NCS mengasumsikan beberapa hal berikut [6]:

(a) sensor bekerja dengan prinsip time-driven, artinya data sinyal keluaran diambil secara periodik,

(b) pengendali bekerja dengan prinsip eventdriven, artinya sinyal kendali dihitung sesaat setelah data sensor diterima,

(c) aktuator bekerja dengan prinsip event-driven, artinya sinyal kendali diberikan kepada aktuator setelah data baru dari pengendali diterima oleh aktuator.
Diagram waktu spesifik yang menggambarkan mekanisme kerja dari sensor, pengendali, dan aktuator dalam NCS dilukiskan pada Gambar 3 [7]. Perhatikan bahwa adanya waktu tunda transmisi data dari sensor ke pengendali $\left(\tau_{\mathrm{i}}^{\mathrm{s}}\right)$ dan dari pengendali ke aktuator $\left(\tau_{i}^{\mathrm{a}}\right)$ menyebabkan sinyal yang dikirimkan ke plant terlambat sebesar $\tau_{i}^{\mathrm{s}}+\tau_{\mathrm{i}}^{\mathrm{a}}$. Keterlambatan respon sinyal kendali akan lebih lama apabila terjadi kehilangan paket data selama transmisi (packet loss). Pemodelan NCS melalui Markovian Jump System (MJS) dimulai dengan menyatakan dinamika sistemnya melalui persamaan ruang keadaan dengan entri-entri matriks-matriks sistemnya fungsi dari state rantai Markovnya. State tersebut biasanya disebut mode sistem dan menyatakan kondisi operasi sistem. Representasi MJS kemudian menjadi lengkap dengan mendefinisikan himpunan yang membangun state sekaligus probabilitas transisi state-state tersebut.

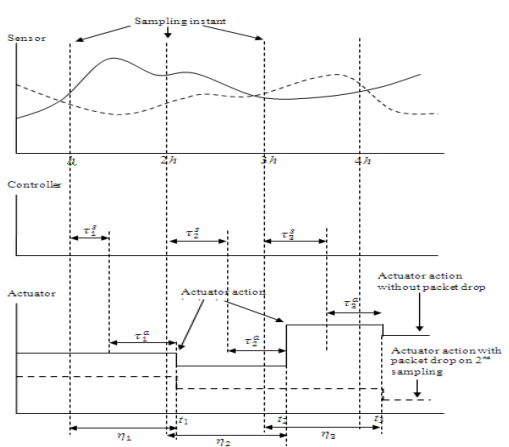

Gambar 3. Diagram waktu NCS

Persamaan ruang keadaan untuk MJS dalam bentuk diskrit dinyatakan dalam bentuk berikut :

$$
\left\{\begin{array}{c}
x(k+1)=A\left(\theta_{k}\right) x(k)+B\left(\theta_{k}\right) u(k) \\
y(k)=C\left(\theta_{k}\right) x(k)+D\left(\theta_{k}\right) u(k)
\end{array}\right.
$$

dengan $x(k)$ menyatakan state sistem, $u(k)$ adalah sinyal input ke sistem, $y(k)$ menandai sinyal output dari sistem, dan $\theta_{k}$ adalah state dari rantai Markov yang terdefinisi dalam himpunan $S=\{1,2, \ldots, N\}$ dan probabilitas transisi dari satu state ke state lain ditandai dengan $p_{i j}$ dengan $i$ dan $j$ adalah anggota dari himpunan S. Nilai untuk $p_{i j}$ berada diantara 0 dan 1 serta jumlah probabilitas transisi dari satu state tertentu ke state lainnya berharga 1 atau $\sum_{j=1}^{N} p_{i j}=1$. Untuk memudahkan penulisan, setiap matriks sistem ditandai dengan $A_{i}, B_{i}, C_{i}$, dan $D_{i}$, saat statenya bernilai $\theta_{k}=i$. State Markov biasanya menandai parameter dalam jaringan. Misalnya parameter jaringan yang dipertimbangkan berupa kondisi transmisi data, maka state Markov yang dipilih berjumlah dua, yaitu state pertama untuk menandai keadaan saat transmisi data yang sempurna antar komponen dan state kedua menyatakan kondisi ketika terjadi packet dropout. 
Gambar 4 memperlihatkan contoh rantai Markov dengan dua variabel state dengan $\alpha$ menandai probabilitas transisi dari mode 1 ke mode 1 atau dari mode 2 ke mode 1 , sedangkan $(1-\alpha)$ adalah probabilitas transisi dari mode 1 ke mode 2 atau dari mode 2 ke mode 2.

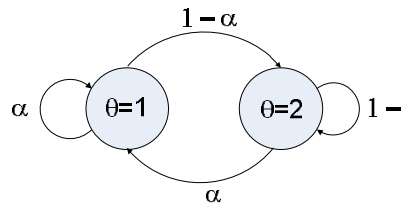

Gambar 4. Rantai Markov dengan dua state

Ishii (2008) dalam [8] menggambarkan NCS yang bergantung kepada salah satu parameter jaringan yaitu adanya paket data yang hilang seperti diperlihatkan pada Gambar 5.

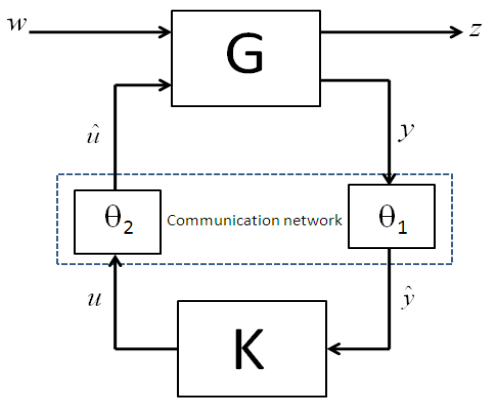

Gambar 5. NCS dengan parameter jaringan $\theta_{\mathrm{i}}$

Dalam Gambar 5, w adalah sinyal input yang biasanya digunakan untuk menandai sinyal gangguan, $z$ adalah sinyal output, $y$ adalah sinyal output yang diukur menggunakan sensor, dan $u$ adalah sinyal yang dihasilkan oleh pengendali untuk dikirim ke aktuator. Dengan adanya parameter jaringan komunikasi, sinyal $y$ yang dikirim ke pengendali akan bergantung kepada parameter jaringan komunikasi, sehingga nilainya bisa berubah menjadi $\hat{y}$. Demikian pula, sinyal dari pengendali yang dikirim ke aktuator melalui jaringan komunikasi akan bergantung kepada parameter jaringan komunikasi sehingga nilainya mungkin berubah menjadi $\hat{u}$. G menandai bagian plant dan aktuator, sedangkan $\mathrm{K}$ adalah pengendali yang akan dirancang. Sementara itu, $\theta_{1}$ menandai parameter jaringan untuk pengiriman data dari sensor ke pengendali, sedangkan $\theta_{2}$ menandai parameter jaringan untuk pengiriman data dari pengendali ke aktuator. Salahsatu bentuk pemilihan state pada rantai Markov-nya didasarkan pada kondisi apakah data yang ditransmisikan sempurna atau ada yang hilang. Dengan parameter tersebut, statenya dapat dituliskan dalam bentuk berikut:

$$
\theta_{i}=\left\{\begin{array}{c}
0, \text { terjadi packet loss } \\
1, \text { seluruh paket diterima }
\end{array}\right.
$$

Dengan mempertimbangkan dua parameter tersebut, dua buah rantai Markov dapat diperoleh seperti yang diperlihatkan dalam Gambar 6.

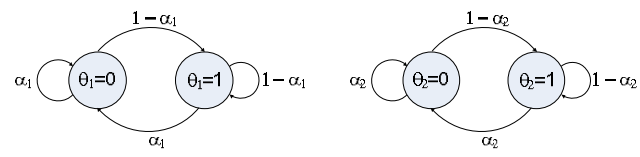

Gambar 6. Dua rantai Markov untuk memodelkan transmisi data dalam jaringan komunikasi

Dari rantai Markov yang diperoleh, sebuah variabel $r(k)$ yang menandai state pada rantai Markov secara keseluruhan dapat didefinisikan dalam bentuk berikut:

$$
r_{k}=\left\{\begin{array}{l}
1,\left(\theta_{1}(k), \theta_{2}(k)\right)=(0,0) \\
2,\left(\theta_{1}(k), \theta_{2}(k)\right)=(0,1) \\
3,\left(\theta_{1}(k), \theta_{2}(k)\right)=(1,0) \\
4,\left(\theta_{1}(k), \theta_{2}(k)\right)=(1,1)
\end{array}\right.
$$

Mengikuti notasi sinyal yang ada dalam sistem NCS seperti pada Gambar 5, persamaan matematis yang mendeskripsikan NCS dalam bentuk MJS dapat dituliskan dalam bentuk berikut:

$$
G\left\{\begin{array}{c}
x(k+1)=A(r(k)) x(k)+B_{1}(r(k)) \hat{u}(k)+B_{2}(r(k)) w(k) \\
z(k)=C_{z}(r(k)) x(k)+D_{z 1}(r(k)) \hat{u}(k)+D_{z 2}(r(k)) w(k) \\
y(k)=C_{y}(r(k)) x(k)+D_{y}(r(k)) w(k)
\end{array}\right.
$$

Ada tiga skema umpan balik yang dapat dipilih berdasarkan keberadaan sensor dan bentuk pengendalimya, yaitu umpan balik keadaan (state feedback), umpan balik output statis (static output feedback), dan umpan balik output dinamis (dynamic output feedback). Perancangan umpan balik yang pertama mengasumsikan bahwa informasi semua variabel keadaan dapat diperoleh secara langsung. Dengan demikian, perancang mengetahui secara eksak tentang variabel keadaaan tersebut. Beberapa hasil penelitian memanfaatkan umpan balik keadaan dalam desain NCS [9-12]. Sementara itu, pendekatan kedua dan ketiga dilakukan apabila perancang hanya memanfaatkan data sensor yang mendeteksi sinyal keluaran dari subsistem yang dikendalikan. Perbedaan antara tipe umpan balik statis dan dinamis terletak pada representasi dinamika pengendalinya. Sebuah pengendali umpan balik keluaran disebut statis apabila perancang harus menemukan gain yang sesuai dengan tujuan pengendaliannya, yang lainnya disebut dinamis apabila representasi ruang keadaan dari pengendalinya diketahui secara lengkap. Beberapa hasil penelitian yang menggunakan umpan balik output dalam desain pengendali NCSnya dilaporkan dalam makalah [8, 13-16]. 


\section{Analisis dan sintesis pengendali dengan umpan balik keadaan}

Dalam makalah ini, skema umpan baliknya menggunakan variabel keadaan, sehingga sinyal $y$ pada Gambar 5 diasumsikan sama dengan variabel keadaan sistem yang dideteksi oleh sensor. Dalam bentuk MJS, persamaan ruang keadaan untuk $\mathrm{G}$ dan pengendali $\mathrm{K}$ untuk skema umpan balik keadaan berturut-turut adalah sebagai berikut:

$$
G\left\{\begin{array}{l}
x(k+1)=A(r(k)) x(k)+B_{1}(r(k)) u(k)+B_{2}(r(k)) w(k) \\
z(k)=C_{z}(r(k)) x(k)+D_{z 1}(r(k)) u(k)+D_{z 2}(r(k)) w(k)
\end{array}\right.
$$

$$
K: u(k)=K(r(k)) x(k)
$$

Tujuan pengendalian dalam sistem ini adalah merancang pengendali dengan cara menemukan nilai $K(r(k))$ sedemikian sehingga sistem NCS lingkar tertutupnya bersifat stabil dan disipatif meskipun adanya parameter jaringan yang dimodelkan oleh state $r(k)$ dalam rantai Markovnya. Stabilitas sistem mengandung pengertian bahwa sistem tersebut tidak menghasilkan sinyal yang sangat besar (menuju tak hingga) apabila diberikan sinyal input dengan magnituda berhingga $[3,9,10]$. Dalam perspektif respon waktu, sistem stabil memperlihatkan sinyal output yang nilainya terbatas sebagai respon terhadap sinyal input yang terbatas. Sementara itu, disipativitas berkaitan dengan pemenuhan kondisi yang menghubungkan sinyal input dan sinyal output dalam bentuk tertentu. Contoh disipativitas sistem adalah kekokohan sistem terhadap sinyal gangguan yang masuk ke dalam sistem [7, 8]. Jaminan stabilitas dan disipativitas untuk sistem MJS yang dinyatakan dalam bentuk persamaan (1) diberikan dalam definisi berikut [17]:

Definisi 1. Sistem (1) bersifat stabil dan disipatif apabila terdapat matriks-matriks $P, Q, M$, dan $R$ yang memenuhi pertidaksamaan matriks berikut:

$$
\left(\begin{array}{cc}
\Psi & \Gamma^{T} \\
\Gamma & \Xi
\end{array}\right)<0
$$

dengan

$$
\begin{aligned}
& \Psi=A_{i}^{T} P_{p i} A_{i}-P_{i}-C_{i}^{T} Q C_{i} \\
& \Gamma=B_{i}^{T} P_{p i} A_{i}-\left(Q D_{i}+M\right)^{T} C_{i} \\
& \Xi=B_{i}^{T} P_{p i} B_{i}-\left(R+M^{T} D_{i}+D_{i}^{T} M+D_{i}^{T} Q D_{i}\right) \\
& P_{p i}=\sum_{j=1}^{N} p_{i j} P_{j}, \forall i, j \in S
\end{aligned}
$$

Dengan menggunakan Definisi 1, stabilitas dan disipativitas sistem NCS lingkar tertutup (5)-(6) diberikan dalam teorema berikut:
Teorema 1. Sistem NCS (5)-(6) dengan parameter jaringan tertentu bersifat stabil dan disipatif apabila dapat ditemukan matriks simetrik $\Psi_{I}$ dan matriksmatriks $\Pi_{I}, G_{i}, H_{i}$, dan $Z_{i j}$ dengan dimensi yang bersesuaian yang memenuhi pertidaksamaan matriks

$$
\left(\begin{array}{cccc}
\alpha & \beta^{T} & \gamma^{T} & \delta^{T} \\
\beta & \chi & \phi^{T} & \eta^{T} \\
\gamma & \phi & \pi & 0 \\
\delta & \eta & 0 & \mu
\end{array}\right)>0
$$

$$
\begin{aligned}
& \text { dengan } \\
& \alpha=\Pi_{i}+\Pi_{i}^{T}-\Psi_{i} \quad \gamma=\left(A_{i} \Pi_{i}+B_{1 i} G_{i}\right) \\
& \beta=S\left(C_{i} \Pi_{i}+D_{z 1 i} G_{i}\right) \quad \delta=-Q\left(C_{z i} \Pi_{i}+D_{z 1 i} G_{i}\right) \\
& \chi=R+M^{T} D_{z 2 i}+D_{z 2 i}^{T} M \\
& \phi=B_{2 i} \\
& \pi=H_{i}+H_{i}^{T}-Z_{p i} \\
& \eta=-Q D_{z 2 i} \\
& \mu=-Q
\end{aligned}
$$

Jika pertidaksamaan matriks (8) memiliki solusi maka nilai $K$ untuk pengendalinya dapat ditentukan dari bentuk berikut:

$$
K_{i}=G_{i} \Pi_{i}^{-1}
$$

\section{Hasil simulasi dan diskusi}

Untuk menguji keefektifan dari metode perancangan yang diuraikan dalam bagian sebelumnya, sebuah simulasi numerik diperlihatkan dalam bagian ini. Sistem yang diambil dalam simulasi ini berupa pengendalian posisi dan kecepatan motor DC melalui jaringan komunikasi dengan parameter jaringan komunikasi berupa packet loss. Diagram sistem kendalinya diperlihatkan pada Gambar 7. Variabel keadaan yang dideteksi oleh sensor berupa kecepatan dan posisi dan dikirim melalui jaringan komunikasi setelah diubah menjadi sinyal digital oleh peralatan ADC. Pengendali menerima sinyal masukan berupa variabel keadaan dan menghasilkan sinyal kendali berbentuk

$$
u(k)=K(r(k)) x(k)
$$

dengan $K(r(k))$ adalah matriks penguatan yang berbentuk matriks baris berdimensi $1 \times 2$.

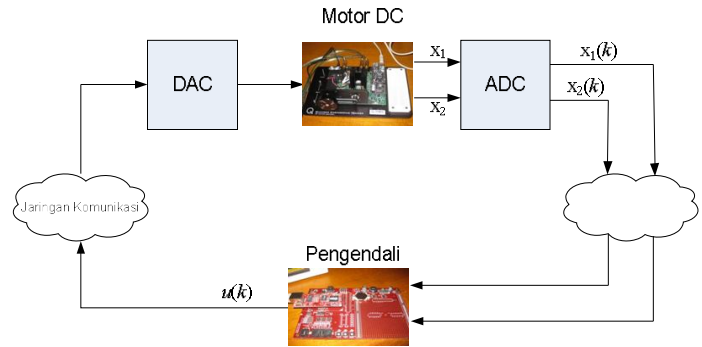

Gambar 7. Pengendalian Motor DC melalui jaringan komunikasi 
Dalam simulasi ini, pengendali yang dirancang mengikuti metode yang diuraikan di bagian 3 akan diuji kehandalannya terhadap parameter jaringan komunikasi berupa packet loss yang terjadi dalam jaringan. Probabilitas packet loss yang digunakan dalam pengujian memiliki nilai masing-masing $10 \%$, $50 \%$, dan $90 \%$ yang mengindikasikan kondisi jaringan yang baik, sedang, dan buruk. Transisi yang terjadi dalam simulasi diperlihatkan pada Gambar 8.

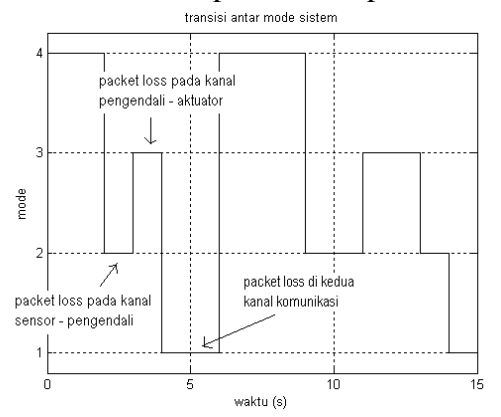

Gambar 8. Transisi antar mode dalam simulasi

Hasil simulasi yang memperlihatkan respon waktu diperlihatkan pada Gambar 9-11. Secara umum terlihat bahwa pengendali yang dirancang mampu menangani parameter packet loss. Hal ini ditunjukkan dengan sinyal keluaran yang terkendali meskipun adanya packet loss di beberapa transisi mode dalam simulasi. Namun demikian, terlihat bahwa saat terjadi packet loss, nilai variabel keadaan melonjak menjadi lebih besar. Untuk kondisi jaringan yang sangat buruk, yang dalam hal ini ditandai dengan parameter packet loss yang sangat besar, sinyal kendali untuk menangani parameter tersebut bernilai sangat besar. Dengan demikian, terdapat korelasi antara kualitas jaringan komunikasi dengan besar energi sinyal kendali yang diperlukan dalam pengendalian sistem.

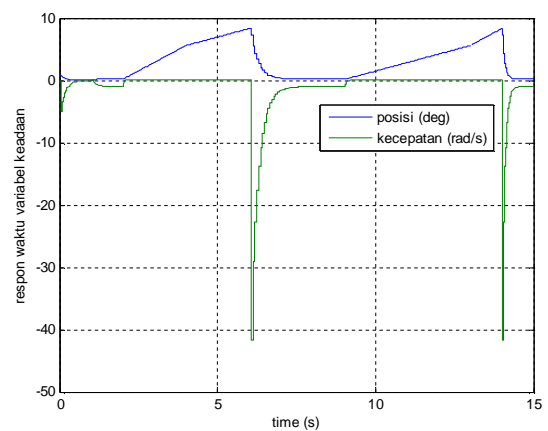

Gambar 9. Respon waktu variabel keadaan untuk probabilitas packet loss $10 \%$

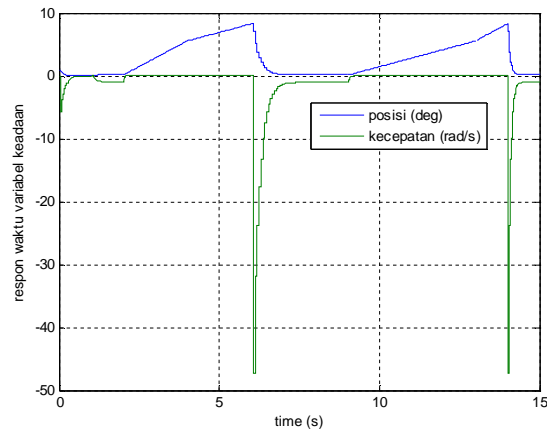

Gambar 10. Respon waktu variabel keadaan untuk probabilitas packet loss $50 \%$

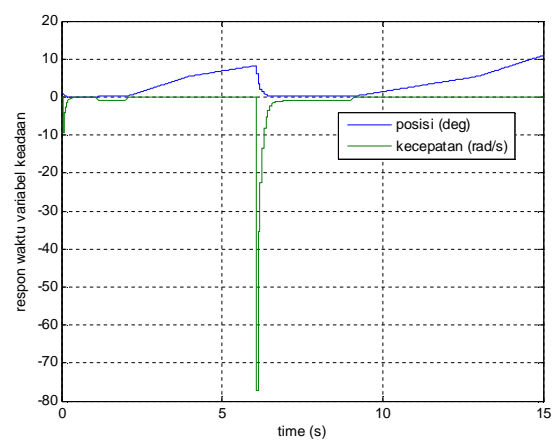

Gambar 11. Respon waktu variabel keadaan untuk probabilitas packet loss $90 \%$

\section{Kesimpulan}

Makalah ini telah menguraikan metode perancangan pengendali untuk networked control systems (NCS) dengan skema umpan balik keadaan yang dimodelkan dengan Markovian jump system (MJS). Pemanfaatan jaringan komunikasi dalam merealisasikan NCS menimbulkan parameter jaringan komunikasi yang tidak bisa dihindarkan. Dalam makalah ini, parameter jaringan komunikasi yang muncul dimodelkan dengan state dalam rantai Markov sehingga menghasilkan bentuk MJS dalam pemodelan NCSnya. Sebuah pengendali dengan umpan balik keadaan dapat menghasilkan stabilitas dan disipativitas sistem NCS lingkar tertutup apabila ditemukan solusi dari sebuah pertidaksamaan matriks yang didalamnya mengandung matriksmatriks sistem dan variabel matriks yang akan membangun pengendalinya. Hasil simulasi berupa pengendalian motor DC melalui jaringan komunikasi memperlihatkan keefektifan dari metode perancangan yang diusulkan, artinya pengendali yang dirancang mampu mengatasi parameter jaringan komunikasi berupa packet loss. 


\section{Daftar Pustaka}

[1] Yang, S. H., 2011, Internet-based Control Systems, London, Springer-Verlag.

[2] Hespanha, J., Naghshtabrizi, P. dan Xu, Y., 2007, A Survey of Recent Results in Networked Control Systems, Proc. of The IEEE, vol. 95, no. 1, January 2007, pp.138-162

[3] Zhang, W., Branicky, M.S. \& Phillips, S.M., 2001, Stability of Networked Control Systems, IEEE Control Systems Magazine, Vol. 21, 2001, pp. 84 - 99.

[4] Varsakelis, D. H. \& Levine, W. S., 2005, Handbook of Networked and Embedded Control Systems, Birkhauser, Boston.

[5] Heemels, W. P. M. H. \& van de Wouw, N., 2010, Stability and Stabilization of Networked Control Systems dalam A. Bemporad, et al (eds), "Networked Control Systems", SpringerVerlag Berlin Heidelberg, 2010, pp. 203 - 253.

[6] Huang, D. \& Nguang, S. K., 2009, Robust Control for Uncertain Networked Control Systems with Random Delay, Berlin Heidelberg, Springer-Verlag

[7] Ridwan, W. \& Riyanto, B., 2011, $H_{\infty}$ control synthesis for Networked Control Systems with Time Delay System Approach, Proc. International Conf. on Electr. Eng. and Informatics, 17 - 19 July 2011, ITB, Bandung.

[8] Ishii, H., 2008, $H_{\infty}$ control with limited communication and message losses, Systems \& Control Letters (57) 2008, pp. 322 - 331.

[9] Lam, J., Gao, H., \& Wang, C., 2007, Stability Analysis for Continuous Systems with Two Additive Time Varying Delay Components, Systems Control Letters, Vol. 56, No. 1, January 2007, pp. $16-24$.

[10] Boukas, E. K., 2008, On stability and stabilization of continuous-time singular Markovian switching systems, IET Control Theory Appl., Vol. 2, No. 10, pp. 884 - 894.

[11] Gao, H., Chen, T., \& Lam, J., 2008, A New Delay System Approach to Network-based Control, Automatica Vol. 44, No. 1, January 2008, pp. $39-52$

[12] Najmurrokhman, A., dkk., 2011, Perancangan Pengendali dengan Umpan Balik Keadaan untuk Networked Control Systems, Prosiding Seminar Nasional Multidisiplin Ilmu Universitas Budi Luhur, 7 Oktober 2011, pp. 27-35.

[13] Arifin, I. \& Riyanto, B., 2007, Output Feedback $\mathrm{H}_{2}$ Synthesis of Networked Control Systems, Int. Conf. on Intelligent Unmanned Systems, October, 2007.

[14] Aberkane, S., Ponsart, J.C. \& Sauter, D., 2008, Output-Feedback $\mathrm{H}_{2} / \mathrm{H}_{\infty}$ Control of A Class of Networked Fault Tolerant Control Systems, Asian Journal of Control Vol. 10, No. 1, January 2008, pp. $34-44$.
[15] Rasool, F., Nguang, S. K. \& Krug, M., 2011, Robust $H \infty$ output feedback control of networked control systems with multiple quantizers, Proc. of IEEE Conf. on Industrial Electronics and Applications, 21-23 June 2011, pp. 1541-1546.

[16] Najmurrokhman, A., dkk., 2011, Output Feedback Controller Design for a class of Networked Control Systems via Markovian Jump System Approach, Proceedings The 2011 ASEAN Symposium on Automatic Control, Ho Chi Minh University of Technology, Ho Chi Minh City, Vietnam, 8-9 November 2011, pp. 98-103.

[17] Najmurrokhman, A., dkk., 2013, Dissipative Controller Design for Networked Control Systems via the Markovian Jump System Approach, Journal of Engineering and Technological Sciences, Vol. 45, No. 1, April 2013, pp. 25-46. 